\title{
Leukocytoclastic Vasculitis and Renal Cell Carcinoma
}

\author{
Dua Cebeci ${ }^{1}$, Şirin Yaşar ${ }^{1}$, Hüsna Güder ${ }^{1}$, Fatih Göktay ${ }^{1}$, Pembe Gül Güneş² ${ }^{2}$ Sema Aytekin ${ }^{1}$ \\ ${ }^{1}$ Department of Dermatology, Haydarpaşa Numune Training and Research Hospital, Istanbul, Turkey \\ ${ }^{2}$ Department of Pathology, Haydarpaşa Numune Training and Research Hospital, Istanbul, Turkey
}

\begin{abstract}
Leukocytoclastic vasculitis (LCV) is the most common form of cutaneous vasculitis, which represents inflammation of small vessels in the skin stemming from immune complex deposition. The disease can affect several organs of the body, such as the kidneys, central nervous system, heart, gastrointestinal tract, and lungs, or it can be confined to only the skin. LCV clinically presents with an eruption of palpable purpuric papules, which may have central vesicles or pustules and may coalesce into larger plaques. LCV causative factors or associated diseases are usually drugs, infection, and rheumatic or collagen vascular disease but rarely malignancies. There are few studies on LCV associated with renal cell carcinoma (RCC). We report the case of our patient with LCV leading to the discovery of an asymptomatic, surgically curable RCC of the kidney.

Keywords: Vasculitis; renal cell carcinoma; kidney.
\end{abstract}

eukocytoclastic vasculitis (LCV) is the most common form of cutaneous vasculitis, which presents with inflammation of small vessels in the skin stemming from immune complex deposition. The disease can affect several organs of the body such as the kidneys, central nervous system, heart, gastrointestinal tract, and lungs or it can be confined to only the skin. LCV clinically presents with an eruption of palpable purpuric papules, which may have central vesicles or pustules and may coalesce into larger plaques ${ }^{[1]}$. LCV causative factors or associated diseases are usually drugs, infection, and rheumatic or collagen vascular disease but rarely malignancies ${ }^{[2]}$. There are few studies on LCV associated with renal cell carcinoma (RCC). We report the case of our patient with LCV leading to the discovery of an asymptomatic, surgically curable RCC of the kidney.

A 65-year-old man was admitted to our dermatology de- partment with a 2-week history of purpuric lesions on the lower extremity. The results of his physical examination were normal. Dermatological examination revealed non-blanching, palpable, purpuric rash involving his lower extremities and gluteal region (Fig 1a, b, c). Laboratory tests revealed that serum C3 and C4 levels, c-ANCA, and amylase were within normal limits and anti-HIV, anti-HCV, and $\mathrm{HBsAg}$ were negative. Microhematuria in urinalysis was remarkable. In the $24-\mathrm{h}$ urine, proteinuria of $0.48 \mathrm{~g} /$ day was found. Ultrasonography of the urinary system revealed a soft tissue mass of $5 \times 5 \mathrm{~cm}$ in the upper pole of the left kidney. Magnetic resonance imaging of the abdomen revealed a massive lesion with solid character extending to the perinefricular fatty tissue in the upper pole of the left kidney. All these findings were found to be consistent with a diagnosis of RCC, and metastatic lymphadenopathies

Correspondence (İletişim): Dua Cebeci, M.D. Department of Dermatology, Haydarpaşa Numune Training and Research Hospital, Istanbul, Turkey Phone (Telefon): +90 2165423232 E-mail (E-posta): perolidua@gmail.com

Submitted Date (Başvuru Tarihi): 06.10.2017 Accepted Date(Kabul Tarihi): 16.11.2017 


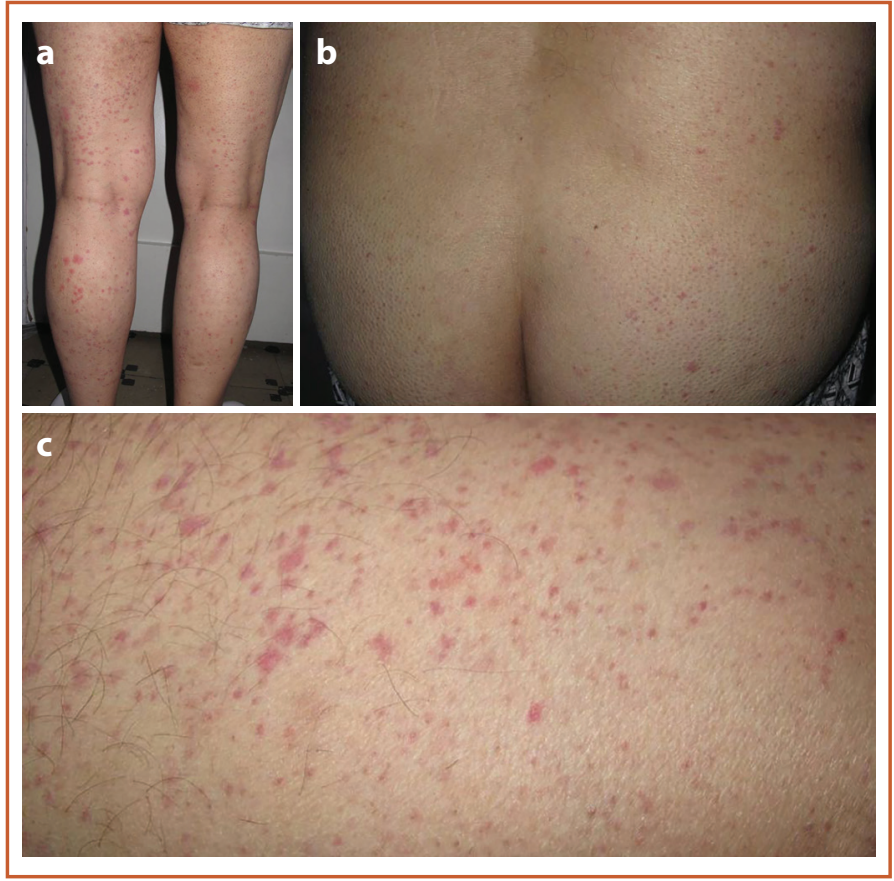

Figure 1. (a-c) Dermatologic examination showed non-blanching, palpable, purpuric rash in his lower extremity and gluteal region.

were detected in the left paraaortic area. A punch biopsy of the rash showed findings characteristic of leukocytoclastic vasculitis: fibrinoid deposits around the vessel wall with perivascular neutrophilic infiltrates in the cutaneous postcapillary venules, endothelial swelling, and erythrocyte extravasation (Fig 2a, b). The patient was diagnosed with LCV and treated with oral antihistamine and leg elevation. He was referred to a urology clinic for simple nephrectomy surgery, and pathological examination of the mass revealed RCC. The vasculitic skin lesions disappeared after surgical treatment, and the general health of the patient was good during a follow-up period of 3 years.

The clinical course of vasculitides is variable, and etiologies or associated conditions are diverse. Some vasculitides can caused by allergy, drugs, rheumatic and/or autoimmune diseases, and infections. In some patients, vasculitis occurs during the course of or prior to malignancies, most often hematogenous malignancies such as leukemia and lymphoma rather than solid tumors ${ }^{[3]}$. Various mechanisms have been proposed for tumor-associated LCV, including antigen-antibody complexes that form in response to tumor antigens and are deposited in the vessel walls, resulting in inflammation ${ }^{[4]}$. Malignancy plays a role in $5 \%$ of patients with LCV ${ }^{[5]}$. In conclusion, LCV might be a marker for malignancy, especially in unexplained cases. Early recognition of LCV associated with underlying malignancy may lead to more timely diagnosis, more succes-

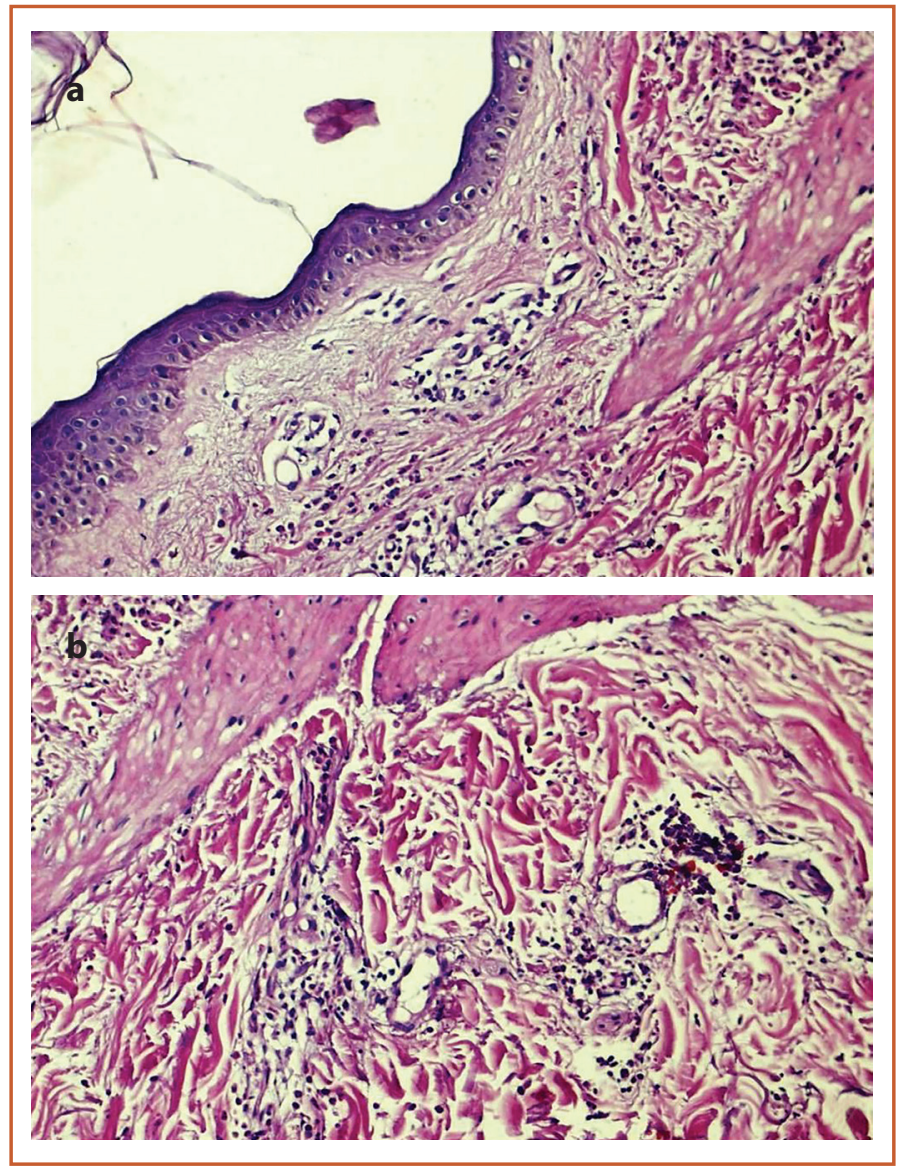

Figure 2. (a, b) Fibrinoid deposits around the vessel wall with perivascular neutrophilic infiltrates in the cutaneous postcapillary venules, endothelial swelling, and erythrocyte extravasation.

sful treatment, and increased survival. We believe that in apparently idiopathic LCV, screening examination should be performed to detect any underlying early-stage curable solid malignancy. Consequently, patients who present with vasculitis of unknown cause, especially in those aged $\geq 50$ years, should be investigated for an associated hidden malignancy.

Informed Consent: Approval was obtained from the patients. Peer-review: Externally peer-reviewed.

Conflict of Interest: None declared.

Authorship Contributions: Concept: D.C., S.Y.; Design: H.G.; Data Collection or Processing: D.C.; Analysis or Interpretation: S.A., F.G., P.G.G.; Literature Search: D.C.; Writing: D.C., S.Y.

Financial Disclosure: The authors declared that this study received no financial support.

\section{References}

1. Podjasek JO, Wetter DA, Pittelkow MR, Wada DA. Cutaneous small-vessel vasculitis associated with solid organ malignan- 
cies: the Mayo Clinic experience, 1996 to 2009. J Am Acad Dermatol 2012;66:e55-65. [CrossRef]

2. Lacour JP, Castanet J, Perrin C, Vitetta A, Ortonne JP. Cutaneous leukocytoclastic vasculitis and renal cancer: two cases. Am J Med 1993;94:104-8. [CrossRef]

3. Fain $O$, Hamidou M, Cacoub P, Godeau B, Wechsler B, Pariès $J$, et al. Vasculitides associated with malignancies: analysis of sixty patients. Arthritis Rheum 2007;57:1473-80. [CrossRef]

4. Greer JM, Longley S, Edwards NL, Elfenbein GJ, Panush RS. Vasculitis associated with malignancy. Experience with 13 patients and literature review. Medicine (Baltimore) 1988;67:220-30. [CrossRef]

5. Jessop SJ. Cutaneous leucocytoclastic vasculitis: a clinical and aetiological study. Br J Rheumatol 1995;34:942-5. [CrossRef] 